\title{
The early phase transcriptome of bovine monocyte-derived macrophages infected with Staphylococcus aureus in vitro
}

Anna Monika Lewandowska-Sabat ${ }^{1 \dagger}$, Guro Margrethe Boman ${ }^{1 \dagger}$, Alison Downing ${ }^{2}$, Richard Talbot ${ }^{2}$, Anne Kristine Storset ${ }^{3}$ and Ingrid Olsaker ${ }^{1 *}$

\begin{abstract}
Background: In the mammary gland, local recruitment and action of macrophages is a key immunological defence mechanism against infection. Macrophages are members of the innate immune system, serve as the first line of the defence against invading pathogens and are critical effectors and regulators of inflammation. We have examined the early phase response of bovine macrophages to infection with live Staphylococcus aureus. Genome-wide transcript profiling of blood monocyte-derived macrophages from six Norwegian Red heifers infected with live S. aureus for 2 and 6 hours in vitro was performed.

Results: About 420 of the 17000 genes on the ARK-Genomics bovine CDNA array were differentially regulated at 6 hours post infection. Approximately $70 \%$ of the responding genes had a known identity (Entrez Gene ID) and were used in the identification of overrepresented pathways and biological functions in the dataset.

Analysis of a subset of differentially regulated genes (List eQG) obtained by comparison with data from genome-wide association mapping in Norwegian Red cattle identified anti-inflammatory cytokines interleukin 4 and interleukin 13 as putative expression quantitative trait loci, suggesting that $S$. aureus infection triggers alternative activation of macrophages. Moreover, several classical activation pathways were found, mainly cellular immune response and cytokine signaling pathways, i.e. triggering receptor expressed on myeloid cells 1 (TREM1) and nucleotide-binding and oligomerization domain-like receptor (NLR) pathways. Tumor necrosis factor receptor superfamily member 5 (CD40 ligand) was identified as an upstream regulator which points toward CD40 likely acting as a co-stimulatory receptor during Toll-like receptor 2(TLR2)-mediated inflammatory response of bovine macrophages to $S$. aureus infection. Furthermore, peptidoglycan was identified as an upstream regulator in the List eQG, which indicates that this bacterial cell-wall component might be pivotal in macrophage intracellular bacterial recognition during early inflammation.
\end{abstract}

Conclusions: Here we have shown that in vitro infection of bovine macrophages with live S. aureus induced both alternative and classical activation pathways. Alternative activation of macrophages may be a mechanism contributing to intracellular persistence of $S$. aureus in the course of inflammation such as during mastitis in dairy cattle.

Keywords: Alternative activation, Cattle, Intracellular, Macrophages, Mastitis, Microarray, Staphylococcus aureus

\footnotetext{
* Correspondence: ingrid.olsaker@nvh.no

'Equal contributors

'Department of Basic Sciences and Aquatic Medicine, Norwegian School of Veterinary Science, P.O. Box 8146 Dep, NO-0033 Oslo, Norway

Full list of author information is available at the end of the article
} 


\section{Background}

Mastitis is an inflammatory condition affecting the mammary gland and the most frequent disease resulting in serious economic losses and herd management problems in dairy production. Bovine mastitis is caused by infection with pathogenic bacteria such as Staphylococcus aureus, Streptococcus uberis and Escherichia coli [1].

$S$. aureus is a widespread pathogen of relevance to both human and veterinary medicine. It is a major causative factor of bovine mastitis in Norway (and worldwide), causes clinical and subclinical intramammary infections and produces 200-300 virulence factors. It has been demonstrated that $S$. aureus invades and survives within mammalian host cells and is competent to replicate in the phagosome or escape the phagosome and persist within the host cells, which can induce anti-apoptotic programs in phagocytes [2]. Intracellular survival of S. aureus has been implied as an immune-evasive strategy causing chronic mastitis infections in cattle. Chronically infected animals are sources of recurrent infections and contribute to spreading $S$. aureus to other cows and herds.

Monocytes and macrophages are critical effectors and regulators of inflammation serving as the first line of innate defence against invading pathogens. During inflammation, circulating monocytes migrate from the blood to tissues in response to chemokine signaling where they differentiate into macrophages. Macrophages are capable of phagocytosis and production of both proinflammatory and anti-inflammatory cytokines [3]. In the bovine udder, macrophages are present in the mammary gland interstitium and alveolar cells, defending epithelium from invading pathogens [4]. Local recruitment and action of macrophages in the mammary gland is an essential immunological defence mechanism against infection.

In addition to the classical macrophage activation (M1) induced by interferon gamma (IFNg), where T helper 1 celltype activation of macrophages triggers a pro-inflammatory response required to kill intracellular pathogens, macrophages also undergo alternative activation. Alternatively activated macrophages (M2) are characterized by suppressed production of proinflammatory cytokines, antiinflammatory effects and reduced killing capacity toward pathogens [5,6]. Recently, M2 macrophages have been further divided into three subsets: M2a, induced by the T helper 2 cytokines interleukin 4 (IL-4) and IL-13 and referred to as wound-healing and tissue repair macrophages; M2b, a less understood group; and M2c, stimulated by IL-10 and referred to as regulatory macrophages and deactivators of the immune response [6,7]. It has been proposed that alternative activation of macrophages triggered by the intracellular pathogen Francisella tularensis is a mechanism by which bacteria can evade the host immune response to favor its intracellular survival [8].
Macrophages can also be activated through expression of macrophage surface receptor tumor necrosis factor superfamily member 5 (CD40) and its functional ligation with CD40 ligand (CD154) expressed on activated T helper cells. CD40 signaling in macrophages induces the nuclear factor kappa B (NFKB)-mediated synthesis of pro-inflammatory cytokines including IL-1a, IL-1b and tumor necrosis factor alpha (TNFa), and several chemokines [9]. It has been demonstrated that IFNB1 and TNFa proteins increase expression of CD40 protein in human endothelial cells and blood-derived dendritic cells $[10,11]$, and NFKB complex increases expression of CD40 in murine dendritic cells [12]. Moreover, studies of the intracellular pathogen Toxoplasma gondii have shown that CD40 signaling induces the TNFa-dependent antimicrobial activity of macrophages even in the absence of IFNg and production of reactive nitrogen intermediates, central elements of classically activated macrophages [13].

It has been suggested previously, that $S$. aureus cell wall peptidoglycan is a biological effector with different stimulatory activities for several pattern recognition receptors (PRRs) of immune cells such as Toll-like receptor 2 (TLR2) and cytosolic nucleotide-binding and oligomerization domain (NOD)-containing proteins. However, later studies have reported that $S$. aureus lipoproteins are ligands for TLR2 $[14,15]$ and after engulfment of $S$. aureus by macrophages, the TLR2/TLR6 complex is recruited to phagosomes for an efficient lipoprotein and TLR2 interaction (reviewed in [16]). TLR2 uses a myeloid differentiation primary response gene 88 (MyD88)dependent signaling pathway resulting in NFKB-mediated expression of pro-inflammatory cytokines and chemokines. However, binding of $S$. aureus peptidoglycan components to intracellular NOD2 protein leads to nuclear translocation of NFKB and induction of cytokine production and inflammation (reviewed in [17]).

The aim of this study was to evaluate an early phase gene response of bovine macrophages to infection with live $S$. aureus. Challenging macrophages with live bacteria induces several genes and pathways that are involved in immunological response likely also during intramammary infections. Transcript profiling of blood monocyte-derived macrophages challenged with $S$. aureus for 2 and 6 hours in vitro were assessed by microarray and the expression of selected genes was validated by reverse transcriptionquantitative PCR (RT-qPCR).

\section{Results}

\section{Microarray analysis}

A total of 418 genes were found to be differentially expressed in the infected cells vs. uninfected control cells at $6 \mathrm{~h}$ post infection $(\sim 2.5 \%$ of the transcripts represented on the microarray). Of these, 250 genes were up-regulated, while 168 were down-regulated (Figure 1, Additional file 1: 


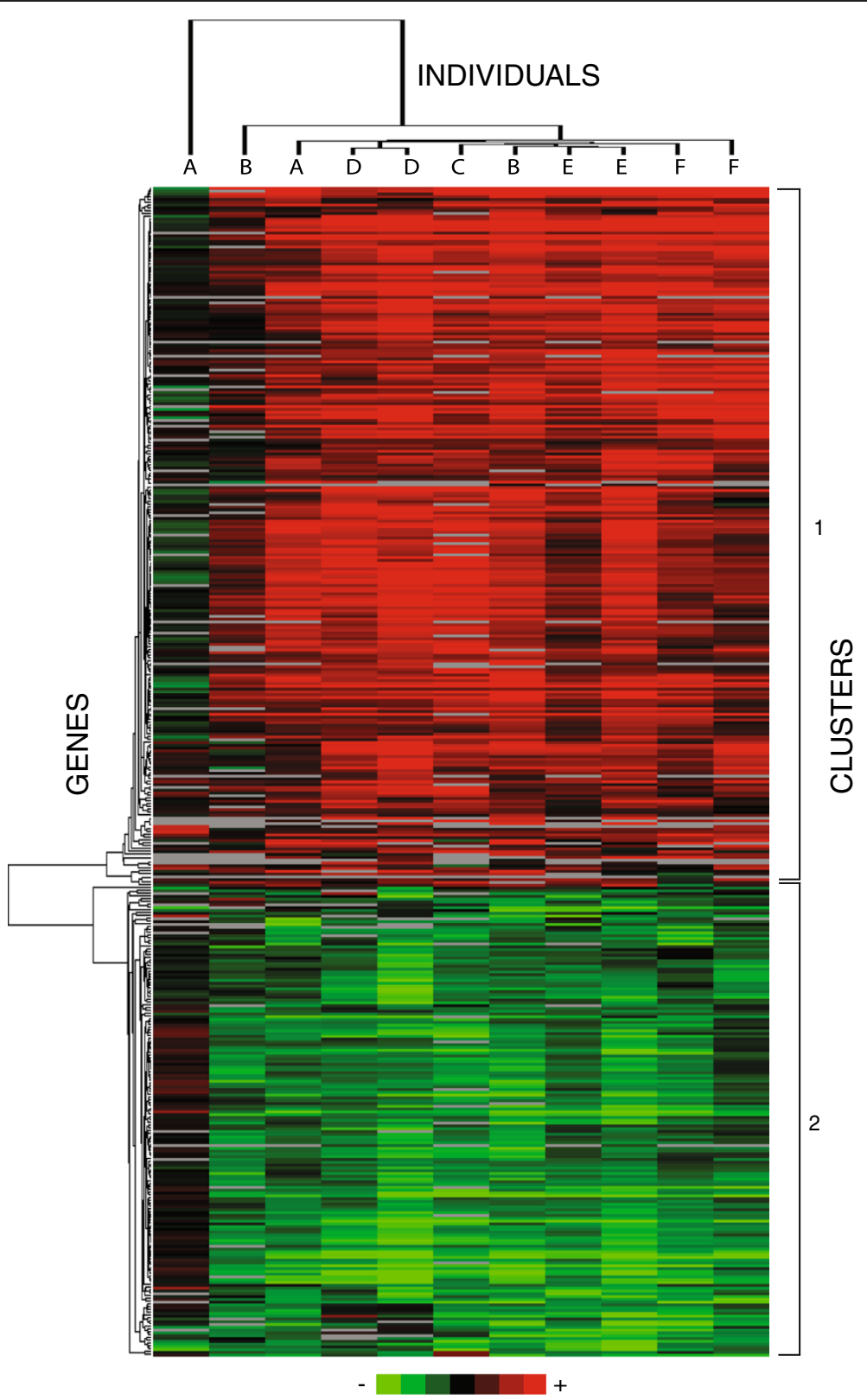

Figure 1 Hierarchical clustering of $\mathbf{4 1 8}$ genes differentially expressed in macrophages in response to Staphylococcus aureus $\mathbf{6}$ hours post infection. Letters (A-F) denote the six Norwegian Red heifers tested in the study. Uninfected control samples of each individual were used as references, i.e. control and Staphylococcus aureus infected samples from one individual were hybridized to one array. Two dye-swaps (arrays) were used per individual except for individual C, where only one array was produced.

Table S1). Fold change values ranged from +11.2 to -4.3 . Out of these 418 genes, 293 obtained gene IDs after Ensembl reannotation ( 70\%). Expression data are deposited in the Array Express Archive (accession: E-TABM-1133). Large variability in the responses between the individuals at the $2 \mathrm{~h}$ time point was observed resulting in no significant regulated genes at this time point (data not shown).

Most of the individuals showed a similar expression pattern at the $6 \mathrm{~h}$ time point. The dye-swap arrays clustered together for 3 individuals (D, E, F), but not for individuals $\mathrm{A}$ and $\mathrm{B}$. Only one array (no dye-swap) was produced for individual $\mathrm{C}$, which clustered with the remaining arrays (Figure 1). Two main clusters of genes were found and the first grouped the up-regulated genes and second grouped the down-regulated genes (Additional file 1: Table S1).

Database for Annotation, Visualization and Integrated Discovery (DAVID) functional annotation clustering 
revealed that 266 of the differentially expressed and Ensembl reannotated genes mapped to 14 different Kyoto Encyclopedia of Genes and Genomes (KEGG) pathways $(p \leq 0.05)$, mainly signaling in the immune response and apoptosis pathways. A subset of the differentially regulated genes (List eQG) with genomic positions linked to quantitative trait loci (QTL) affecting susceptibility to mastitis in Norwegian Red cattle (NRF) was identified previously [18]. Twenty-five of the List eQG genes were mapped to 5 different KEGG pathways $(p \leq 0.05)$, mainly signaling in immune response and cancer (Table 1). Ingenuity Pathway Analysis (IPA) mapped 281 gene IDs using the Ensembl reannotated differentially expressed genes on microarray, which resulted in identification of 170 canonical pathways ( $p \leq 0.05$, Additional file 2: Table S2a). When the List eQG was used, IPA mapped 25 gene IDs and 65 canonical pathways were identified ( $p \leq 0.05$, Additional file 2: Table $\mathrm{S} 2 \mathrm{~b})$. The top canonical pathways for both gene lists are presented in Table 2.

Top molecular and cellular functions identified by IPA for differentially expressed genes on microarray and List eQG were similar and were associated with death, survival,

\begin{tabular}{|c|c|c|}
\hline & KEGG pathway & $p$-value \\
\hline \multirow[t]{14}{*}{$\bar{A}$} & NOD-like receptor signaling pathway* & $4.9 \times 10^{-7}$ \\
\hline & Cytokine-cytokine receptor interaction* & $1.7 \times 10^{-6}$ \\
\hline & Toll-like receptor signaling pathway* & $6.2 \times 10^{-5}$ \\
\hline & Asthma* & $9.8 \times 10^{-4}$ \\
\hline & T cell receptor signaling pathway & $3.6 \times 10^{-3}$ \\
\hline & Jak-STAT signaling pathway & $4.1 \times 10^{-3}$ \\
\hline & Apoptosis & $4.4 \times 10^{-3}$ \\
\hline & Chemokine signaling pathway & $4.9 \times 10^{-3}$ \\
\hline & Cytosolic DNA-sensing pathway & $1.4 \times 10^{-2}$ \\
\hline & Allograft rejection & $2.6 \times 10^{-2}$ \\
\hline & RIG-I-like receptor signaling pathway & $3.0 \times 10^{-2}$ \\
\hline & Sphingolipid metabolism & $3.0 \times 10^{-2}$ \\
\hline & Natural killer cell mediated cytotoxicity & $4.8 \times 10^{-2}$ \\
\hline & Fc epsilon RI signaling pathway & $4.8 \times 10^{-2}$ \\
\hline \multirow[t]{5}{*}{$\mathrm{B}$} & Cytokine-cytokine receptor interaction* & $5.2 \times 10^{-4}$ \\
\hline & Jak-STAT signaling pathway & $2.8 \times 10^{-3}$ \\
\hline & Colorectal cancer & $1.4 \times 10^{-2}$ \\
\hline & Toll-like receptor signaling pathway & $1.8 \times 10^{-2}$ \\
\hline & Pathways in cancer & $2.6 \times 10^{-2}$ \\
\hline
\end{tabular}

A) The list of differentially regulated on microarray $(n=418)$ and Ensembl reannotated genes was used as an input for functional annotation clustering; B) Subset of these genes ( $n=28$; List eQG from [18]) was used as an input. Asterisk (*) denotes the significant KEGG pathways after the BenjaminiHochberg multiple testing correction $(p \leq 0.05)$. function and movement of immune cells (Table 3). All biological functions identified in IPA for both datasets are presented in Additional file 3: Table S3.

Top networks mainly associated with cell-to-cell signaling and interaction, cell-mediated immune response and antimicrobial response were identified in IPA for the differentially expressed genes on microarray, while cell death and survival, cellular movement and immune cell trafficking were identified for List eQG (Table 4). All networks identified in IPA for both datasets are presented in Additional file 4: Table S4. The most striking functional network found to be over-represented in differentially expressed genes on the microarray involved NFKB and its associated molecules (Figure 2). For List eQG overrepresented functional network involved $I L-4, I L-13$, suppressor of cytokine signalling 3 (SOCS3) and its associated molecules (Figure 3).

The top upstream regulator identified in IPA for differentially expressed genes on the microarray was CD154 and for List eQG it was peptidoglycan. The top upstream regulators for both datasets are presented in Table 5 and all identified upstream regulators are presented in Additional file 5: Table S5. CD154 and peptidoglycan, and its target molecules in datasets are presented in Figure 4A and B, respectively.

\section{Verification of microarray data by RT-qPCR}

Ten out of thirteen genes selected for verification of the microarray results showed a significant difference in expression between $S$. aureus infected and uninfected control cells $(p \leq 0.05)$. Eight of these differentially expressed genes confirmed the expression pattern on the microarray [chemokine c-c motif ligand 5 (CCL5), chemokine c-c motif receptor 5 (CCR5), intercellular adhesion molecule-1 (ICAM1), interferon regulatory factor 1 (IRF1), mitogenactivated protein kinase 14, p38 (MAPK14), p21/cdc42/ rac1-activated kinase 1 (PAK1), TLR8 and TNFa], and two of the genes [bcl2-antagonist of cell death $(B A D)$, and remodeling and spacing factor 1 (RSF1)] showed a divergent expression pattern in the RT-qPCR analysis compared to the microarray experiment. Caspase 1 (CASP1), $v$-fos $f b j$ murine osteosarcoma viral oncogene homolog (FOS) and $I F N b$ were non-significant in the RT-qPCR analysis, i.e. no significant difference in expression was observed between $S$. aureus infected and uninfected control individuals $(p>0.05$; Figure 5). Overall, the RT-qPCR data correlated with the microarray data, 10 significant genes were used in the analyses $(r=0.6)$.

\section{Discussion}

In this study we have investigated gene response of bovine macrophages to in vitro infection with live $S$. aureus in order to illuminate the putative mechanism underlying the early immune response for instance during mastitis in 
Table 2 Top canonical pathways generated by Ingenuity Pathway Analysis (IPA)

\begin{tabular}{|c|c|c|c|c|}
\hline & Ingenuity canonical pathways & $p$-value & Ratio & Molecules \\
\hline \multirow[t]{5}{*}{$\bar{A}$} & TREM1 signaling & $2.71 \times 10^{-11}$ & $1.69 \times 10^{-1}$ & $\begin{array}{l}\text { IL8, CXCL3, ICAM1, CD40, GRB2, IL10, TLR8, CASP1, } \\
\text { IL1B, FCGR2B, NFKB1, TNF }\end{array}$ \\
\hline & Hepatic fibrosis/hepatic stellate cell activation & $8.32 \times 10^{-11}$ & $1.10 \times 10^{-1}$ & $\begin{array}{l}\text { CXCL3, IL8, IL4R, CCR5, ICAM1, CD40, MYL6, IL10, } \\
\text { IL6R, IL1B, IFNGR1, CCL5, NFKB1, TNF, CCR7, IL4 }\end{array}$ \\
\hline & IL-10 signaling & $3.82 \times 10^{-9}$ & $1.41 \times 10^{-1}$ & $\begin{array}{l}\text { TRAF6, SOCS3, FOS, IL4R, CCR5, MAPK14, IL10, IL1B, } \\
\text { FCGR2B, NFKB1, TNF }\end{array}$ \\
\hline & IL-12 signaling and production in macrophages & $6.87 \times 10^{-9}$ & $8.97 \times 10^{-2}$ & $\begin{array}{l}\text { IL10, MAF, IFNGR1, NFKB1, IRF1, TRAF6, FOS, MAPK14, } \\
\text { CD40, ZNF668, NOS2, TNF, PRKD3, IL4 }\end{array}$ \\
\hline & IL-17A signaling in gastric cells & $3.33 \times 10^{-8}$ & $2.80 \times 10^{-1}$ & IL8, FOS, MAPK14, CCL20, CCL5, NFKB1, TNF \\
\hline \multirow[t]{5}{*}{$\bar{B}$} & $\begin{array}{l}\text { Role of cytokines in mediating communication } \\
\text { between immune cells }\end{array}$ & $8.88 \times 10^{-7}$ & $7.27 \times 10^{-2}$ & IL8, IFNB1, IL13, IL4 \\
\hline & $\begin{array}{l}\text { Communication between innate and adaptive } \\
\text { immune cells }\end{array}$ & $6.73 \times 10^{-6}$ & $3.67 \times 10^{-2}$ & IL8, IFNB1, CCR7, IL4 \\
\hline & Airway inflammation in asthma & $1.81 \times 10^{-5}$ & $3.33 \times 10^{-1}$ & IL13, IL4 \\
\hline & Remodeling of epithelial adherens junctions & $1.08 \times 10^{-4}$ & $4.41 \times 10^{-2}$ & ACTR3, MAPRE1, CLIP1 \\
\hline & Prolactin signaling & $1.5 \times 10^{-4}$ & $3.75 \times 10^{-2}$ & SOCS3, FOS, IRF1 \\
\hline
\end{tabular}

A) The list of differentially regulated on microarray $(n=418)$ and Ensembl reannotated genes was used as an input for IPA; B) Subset of these genes ( $=28$; List eQG from [18]) was used as an input.

cattle. Our results have shown that infection of macrophages with $S$. aureus induced both alternative and classical activation pathways. The most pronounced functional network over-represented in the QTL related subset of our data (List eQG) involved anti-inflammatory cytokines $I L-4, I L-13$ and SOCS3 as central molecules and these genes were found to be up-regulated (Figure 3, Table 2B, Additional file 1: Table S1, Additional file 3: Table S3). Moreover, several proinflammatory cytokines classically activated upon TLR2 signaling in response to $S$. aureus were up-regulated in our study (Additional file 1: Table S1),

Table 3 Top molecular and cellular functions identified by Ingenuity Pathway Analysis (IPA)

\begin{tabular}{|c|c|c|c|}
\hline & $\begin{array}{l}\text { Top molecular and } \\
\text { cellular functions }\end{array}$ & $p$-value & $\begin{array}{l}\text { No. of } \\
\text { molecules }\end{array}$ \\
\hline \multirow[t]{5}{*}{$A$} & Cell death and survival & $5.86 \times 10^{-17}-8.33 \times 10^{-6}$ & 114 \\
\hline & $\begin{array}{l}\text { Cellular function and } \\
\text { maintenance }\end{array}$ & $5.21 \times 10^{-16}-5.86 \times 10^{-6}$ & 73 \\
\hline & Cellular movement & $1.79 \times 10^{-13}-7.87 \times 10^{-6}$ & 68 \\
\hline & Cellular development & $2.52 \times 10^{-13}-6.75 \times 10^{-6}$ & 105 \\
\hline & $\begin{array}{l}\text { Cellular growth and } \\
\text { proliferation }\end{array}$ & $2.52 \times 10^{-13}-8.04 \times 10^{-6}$ & 111 \\
\hline \multirow[t]{5}{*}{$\bar{B}$} & Cell death and survival & $7.73 \times 10^{-10}-9.61 \times 10^{-4}$ & 14 \\
\hline & Cellular development & $1.35 \times 10^{-9}-8.97 \times 10^{-4}$ & 18 \\
\hline & $\begin{array}{l}\text { Cellular growth and } \\
\text { proliferation }\end{array}$ & $1.35 \times 10^{-9}-8.97 \times 10^{-4}$ & 18 \\
\hline & Cellular movement & $1.82 \times 10^{-9}-9.32 \times 10^{-4}$ & 14 \\
\hline & $\begin{array}{l}\text { Cellular function and } \\
\text { maintenance }\end{array}$ & $1.06 \times 10^{-8}-9.32 \times 10^{-4}$ & 15 \\
\hline
\end{tabular}

A) The list of differentially regulated on microarray $(n=418)$ and Ensembl reannotated genes was used as an input for IPA; B) Subset of these genes $(n=28$; List eQG from [18]) was used as an input. e.g. $I L-1 b$ and TNFa, and TLR2 was identified as one of the putative upstream regulators (Table 5, Additional file 5: Table S5). It has been shown that TLR2 is involved in prolonged survival of $S$. aureus in macrophage phagosomes, which was explained by TLR2-dependent inhibition of superoxide production [19]. Our data support this study, however we suggest that $S$. aureus infection induces TLR2-dependent alternative activation of macrophages. This is consistent with the model proposed for intracellular bacterial survival of $F$. tularensis. F. tularensis enters macrophages by a TLR2-dependent mechanism that initiates a temporary inflammatory response. The macrophages are induced to produce IL-4 and IL-13 that in turn triggers alternative activation of macrophages and allows F. tularensis to replicate freely. Alternatively activated macrophages produce anti-inflammatory IL-10, which inhibits pro-inflammatory cytokines produced by classically activated macrophages [8]. The up-regulation of $\mathrm{T}$ helper 2 type cytokines $I L-4, I L-13$ and $I L-10$ (Additional file 1 : Table S1) in our study may suggest that $S$. aureus infection has polarized bovine macrophages toward a M2 subset with wound repair $\mathrm{M} 2 \mathrm{a}$ and immunoregulatory and antiinflammatory M2c phenotypes.

Also, it has been demonstrated recently that infection with intracellular Mycobacterium tuberculosis activates the alternative phenotype of macrophages that inhibit autophagy-dependent maturation and killing of mycobacteria, which indicates that alternative activation of macrophages may contribute to the persistence of mycobacterial infection [20]. Furthermore, increased cell survival and viability with several inhibitors of apoptosis was found in our study as one of the top molecular functions and networks (Tables 3 and 4, Additional file 3: Table S3, 
Table 4 Top networks identified by Ingenuity Pathway Analysis (IPA)

\begin{tabular}{|c|c|c|}
\hline & Associated network functions & Score \\
\hline \multirow[t]{5}{*}{ A } & $\begin{array}{l}\text { Cell-to-cell signaling and interaction, cardiovascular } \\
\text { system development and function, cell morphology }\end{array}$ & 30 \\
\hline & $\begin{array}{l}\text { Embryonic development, organismal development, } \\
\text { cell morphology }\end{array}$ & 27 \\
\hline & $\begin{array}{l}\text { Cell-mediated immune response, cellular movement, } \\
\text { hematological system development and function }\end{array}$ & 26 \\
\hline & $\begin{array}{l}\text { Antimicrobial response, cell-to-cell signaling and } \\
\text { interaction, embryonic development }\end{array}$ & 23 \\
\hline & Cell cycle, cellular movement, developmental disorder & 23 \\
\hline \multirow[t]{5}{*}{ B } & $\begin{array}{l}\text { Cell death and survival, cellular function and } \\
\text { maintenance, cellular growth and proliferation }\end{array}$ & 20 \\
\hline & $\begin{array}{l}\text { Cellular movement, hematological system } \\
\text { development and function, immune cell trafficking }\end{array}$ & 14 \\
\hline & $\begin{array}{l}\text { Cellular assembly and organization, cellular } \\
\text { compromise, cellular function and maintenance }\end{array}$ & 8 \\
\hline & $\begin{array}{l}\text { Antimicrobial response, cell-to-cell signaling and } \\
\text { interaction, cellular movement }\end{array}$ & 5 \\
\hline & $\begin{array}{l}\text { Reproductive system disease, embryonic development, } \\
\text { organismal development }\end{array}$ & 3 \\
\hline
\end{tabular}

A) The list of differentially regulated on microarray $(n=418)$ and Ensembl reannotated genes was used as an input for IPA; B) Subset of these genes $(\mathrm{n}=28$; List eQG from [18]) was used as an input.

Additional file 4: Table S4). BAD, baculoviral IAP repeatcontaining 2 (BIRC2), BIRC3 and BIRC5 were found to be up-regulated in response to $S$. aureus infection (Additional file 1: Table S1) and BIRC5 was found among the differentially expressed genes in List eQG (Additional file 3: Table S3). It has been shown that phosphorylation of BAD protein and expression of BIRC5 mRNA increased cell survival $[21,22]$. Moreover, it has been demonstrated that apoptosis in phagocytes can also be modulated by pathogens $[23,24]$ and the increased expression of anti-apoptotic genes in $S$. aureus infected human macrophages is responsible for extended phagocyte lifetime allowing intracellular bacterial survival [25]. Interestingly, BIRC5 and SOCS3 are located in the region of QTL markers associated with somatic cell score (SCS) in NRF [26], and elevated SCS is often an indicator of subclinical mastitis in cattle infected with $S$. aureus. Likely, S. aureus evades the host immune system by induction of anti-inflammatory and anti-apoptotic factors in invaded host cells, which allows the pathogen to persist and replicate in the infected cells during the early stage of inflammation. These findings point toward $I L-4$ and $I L-13$ as possible expression QTL (eQTL) for S. aureus induced mastitis, and SOCS3 and $B I R C 5$ as possible eQTL for chronic infections in cattle.

$C D 40$ and several proinflammatory cytokines e.g. $I L-1 b$, $T N F a$ and $I L-8$ were up-regulated in our dataset, and CD154 was predicted as the most significant upstream regulator (Table 5, Figure 4). Recent studies have shown, that the synergy of TLR2 and CD40 signaling contributes to activation of resting B cells [27] and TLR2 signaling controls an early Listeria monocytogenes infection which involve co-stimulatory molecule CD40 [28]. Moreover, TLR2-dependent activation of NFKB complex and TNFa likely induced co-stimulatory function of CD40 signaling in the absence of other immune activators, such as T helper cells or IFNg $[10,12,13]$. This may suggest that TLR2-dependent activation may also require co-stimulatory function of CD40 for efficient S. aureus lipoproteins-induced signaling in macrophages. It has also been shown that CD40 signaling in macrophages is modulated by IL-4 and IL-10 anti-inflammatory cytokines that act via different mechanisms likely including SOCS $[29,30]$, and IL-10 signaling was found as a top canonical pathway in our dataset (Table 2). This data together with findings that induction of $I L-10$ expression in alternatively activated macrophages is TLR2-dependent suggest that CD40 signaling may likely be controlled by antiinflammatory output of alternative activation of bovine macrophages induced by $S$. aureus infection.

The top KEGG pathway found in DAVID was the nucleotide-binding and oligomerization domain-like receptor (NLR) signaling pathway (Table 1), while the top canonical pathway found in IPA was triggering receptor expressed on myeloid cells 1 (TREM1) signaling (Table 2). The synergy between TLR2 and TREM1 stimulates intracellular signals resulting in phagocytosis and production of proinflammatory cytokines. Additionally, TREM1 signaling induces proinflammatory cytokines in response to bacterial muropeptides via the CASP1-dependent pathway. This signaling involves increased NOD2 gene transcription suggesting that TREM1 acts to amplify the signal also from intracellular NLR proteins [31]. In addition to TNFa and $I L-1 b, C A S P 1$ and NFKB1 were found to be up-regulated in our study (Additional file 1: Table S1) suggesting that TREM1 signaling may likely provide the link between TLR2- and NLR-mediated signal transduction in cytokine-induced inflammation during the initiation of host defense such as in mastitis. Furthermore, the most pronounced functional network over-represented in our data involved NFKB as a central molecule (Figure 2), suggesting that NFKB is a fundamental transcription factor linking TLR2-, CD40- and NLRmediated signaling and induction of proinflammatory activities of macrophages in response to $S$. aureus.

Peptidoglycan was identified as the most significant upstream regulator for the List eQG (Table 5, Figure 4). Previous studies have shown that $S$. aureus lipoteichoic acid (LTA) and/or peptidoglycan activate the macrophages through intracellular NOD signaling [25,32]. It was demonstrated in cattle that the $S$. aureus peptidoglycan component synergized with LTA induced production of chemokines in mammary epithelial cells and neutrophil 


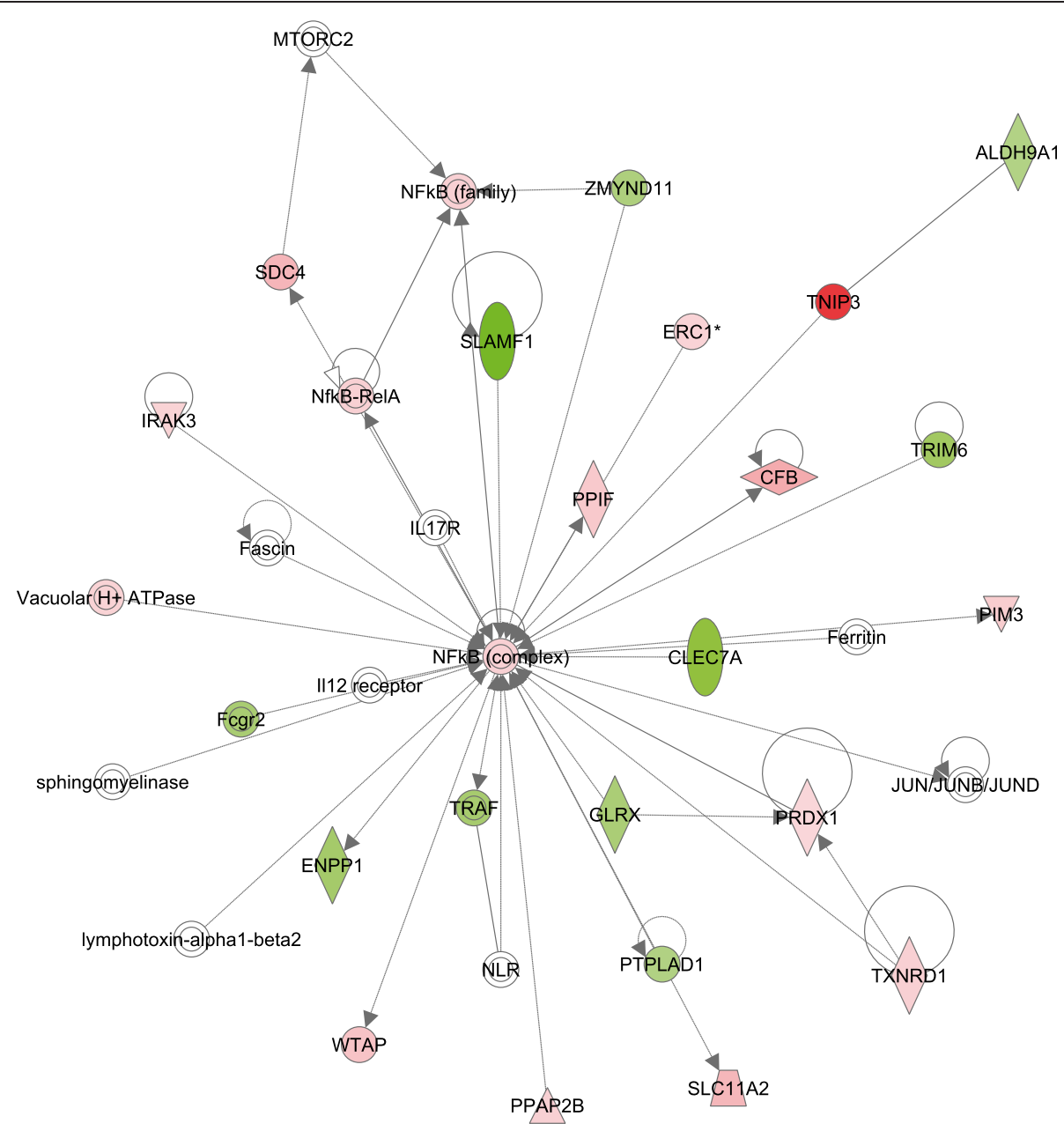

Figure 2 Functional network over-represented in a list of differentially expressed genes on the microarray involving nuclear factor kappa B (NFKB) complex and associated molecules with a network score of 31, as identified by Ingenuity Pathway Analysis (IPA). Red denotes molecules that were up-regulated and green denotes molecules down-regulated in response to 6 hours infection with live Staphylococcus aureus in bovine macrophages.

recruitment in the mammary gland [33]. This is also pronounced in our data, where the top canonical pathway for genes from List eQG was related to 'Role of cytokines in mediating communication between immune cells', with IL-8 and CXC-chemokine ligand 2 (CXCL2) chemokines among the significantly up-regulated genes (Table 2B, Figure 4B). These results suggest that $I L-8$ and $C X C L 2$ may be potential eQTL for neutrophil recruitment during S. aureus induced intramammary infections in cattle. These findings together imply an important role for staphylococcal peptidoglycan in NOD signaling mediated immune response during mastitis in cattle with likely the principal role of neutrophil recruitment, as demonstrated earlier in the mammary gland [34-36]. Intracellular NLR are likely involved in peptidoglycan-induced signaling in macrophages, independent of lipopeptides/TLR2 interaction and signaling as demonstrated earlier [37].
We were not able to identify any significantly differentially expressed genes at the $2 \mathrm{~h}$ time point, while several genes were found at $3 \mathrm{~h}$ p.i in another study [38]. The variation between the individuals in macrophage gene expression in response to $S$. aureus infection was high at the $2 \mathrm{~h}$ time point resulting in the lack of significantly regulated genes. This may be due to relatively low expression level of immune response genes at its earliest stage of bacterial infection when high variation is more pronounced compared to the $6 \mathrm{~h}$ time point.

Our results are in agreement with previous studies of $S$. aureus mastitis in ruminants [38-43]. However, we have identified the anti-inflammatory cytokines $I L-4$ and $I L-13$, which suggests that $S$. aureus infection probably leads to induction of alternative activation of the macrophages (Figure 6). The results of this study may reflect the importance of macrophages in modulating the host 


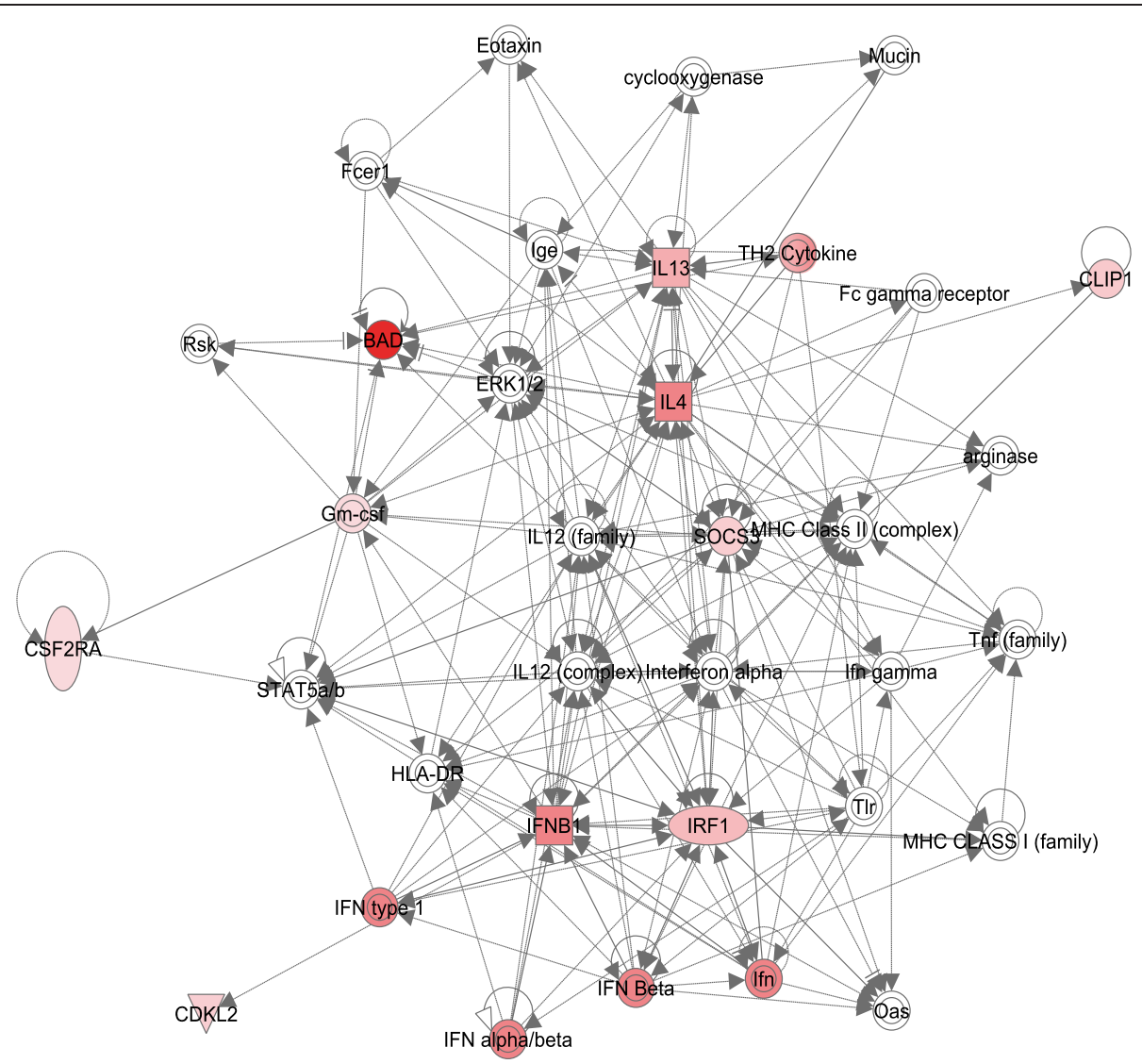

Figure 3 Functional network over-represented in the subset of the differentially regulated genes (List eQG) involving interleukin 4 (IL-4), IL-13 and suppressor of cytokine signalling 3 (SOCS3) and associated molecules with a network score of 20, as identified by Ingenuity Pathway Analysis (IPA). List eQG consist of genes that resulted from combining of the differentially regulated genes on the microarray $(n=418)$ with marker positions from a study of quantitative trait loci $(\mathrm{QTL})$ affecting susceptibility to mastitis in Norwegian Red cattle [26]. Red denotes molecules that were up-regulated in response to 6 hours infection with live Staphylococcus aureus in

Table 5 Top upstream regulators identified by Ingenuity Pathway Analysis (IPA)

\begin{tabular}{lll}
\hline & Top upstream regulators & $\boldsymbol{p}$-value \\
\hline A & CD40 ligand (CD154) & $2.25 \times 10^{-24}$ \\
& TNF receptor superfamily member 5 (CD40) & $1.05 \times 10^{-22}$ \\
& Interleukin 10 (IL-10) & $1.01 \times 10^{-21}$ \\
5'-inosinic acid (poly rl:rC) & $1.73 \times 10^{-20}$ \\
& Lipopolysaccharide (LPS) & $6.21 \times 10^{-20}$ \\
\hline B $\quad$ Peptidoglycan & $1.79 \times 10^{-13}$ \\
& Suppressor of cytokine signaling 1 (SOCS1) & $7.66 \times 10^{-13}$ \\
& Tyrphostin AG490 (AG490) & $1.71 \times 10^{-12}$ \\
& Interleukin 10 (IL-10) & $3.52 \times 10^{-12}$ \\
& Toll-like receptor 2 (TLR2) & $3.55 \times 10^{-12}$ \\
\hline
\end{tabular}

A) The list of differentially regulated on microarray $(n=418)$ and Ensembl reannotated genes was used as an input for IPA; B) Subset of these genes $(n=28$; List eQG from [18]) was used as an input. immune response during mastitis in cattle. It should be noted however, that our data are based on in vitro analysis of blood monocyte-derived macrophages. Consequently, the hypothesis needs to be further evaluated by studies of macrophages from bovine mammary glands infected with S. aureus.

\section{Conclusions}

This study has demonstrated the novel finding that $S$. aureus infection most probably induces TLR2-dependent alternative activation of macrophages which contributes to persisting staphylococcal infection. Moreover, CD40 and TREM1 signaling pathways appear as the most interesting candidates that likely provide the link between TLR2- and NLR-mediated signal transduction determining optimal host defence during mastitis. Our study may reflect the role of macrophages in the immune defense of the udder and contributes to further elucidation of the mechanism of early inflammatory responses such as during mastitis in cattle. 


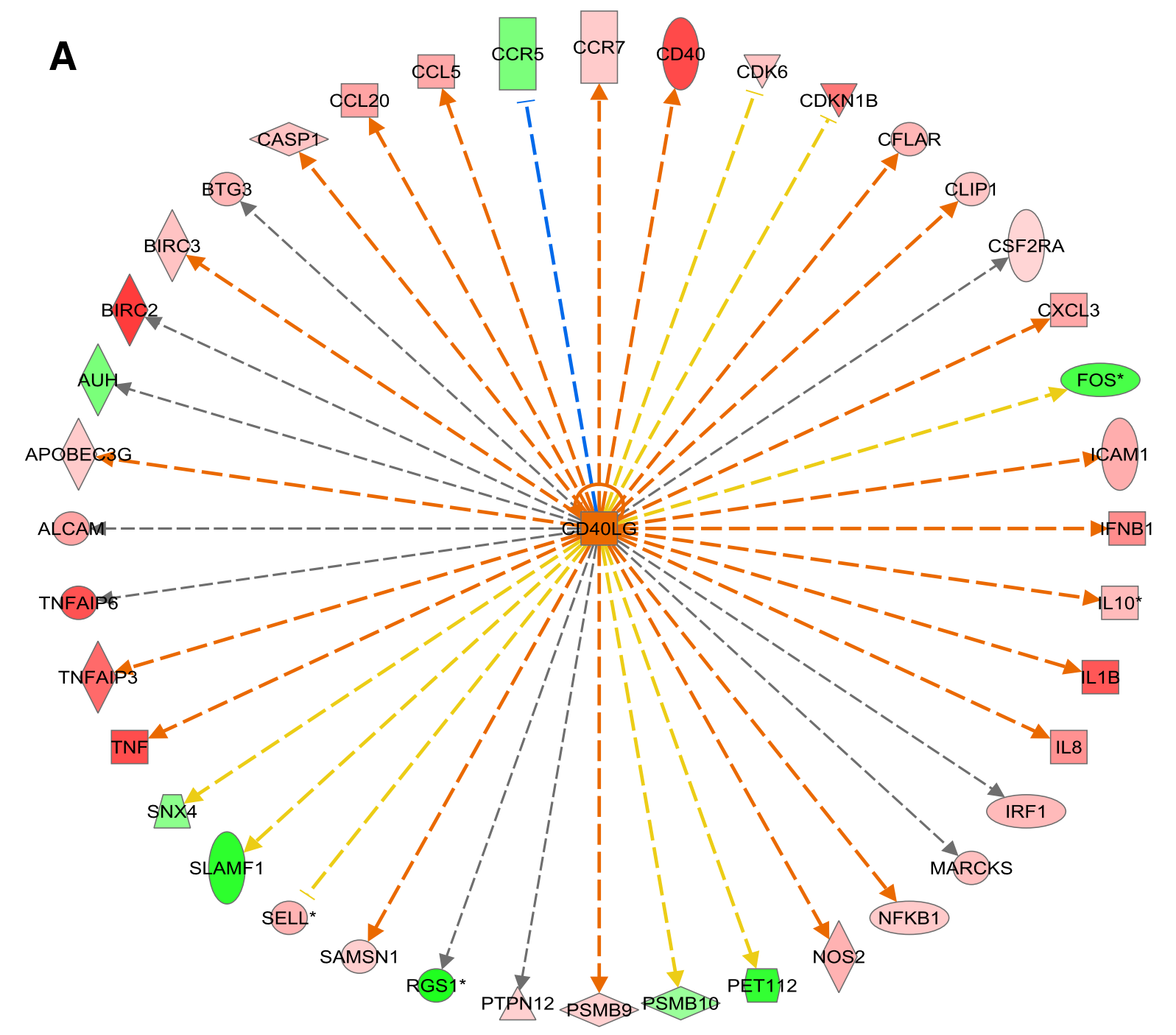

B

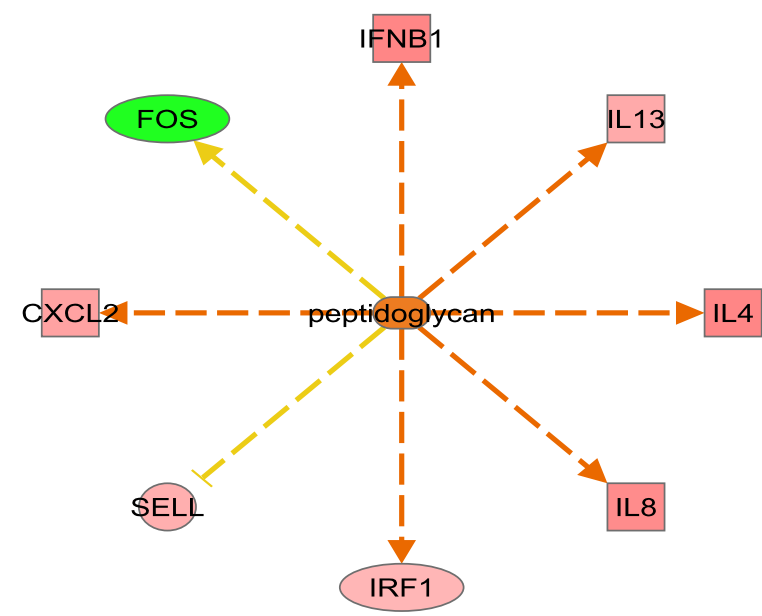

Figure 4 (See legend on next page.) 
(See figure on previous page.)

Figure 4 Upstream regulators and their target molecules in datasets as identified by Ingenuity Pathway Analysis (IPA). A - The list of differentially regulated on microarray $(n=418)$ and Ensembl reannotated genes was used as an input for analysis; $\mathbf{B}$ - Subset of these genes ( $n=28$; List eQG from [18]) was used as an input. Molecules in red denote up-regulation, molecules in green denote down-regulation and molecules in orange denote predicted activation in response to 6 hours infection with live Staphylococcus aureus in bovine macrophages. Lines in orange denote predicted activation; lines in blue - predicted inhibition; lines in yellow - findings inconsistent with state of downstream molecule; and lines in grey - effect not predicted.

\section{Methods}

\section{Animals and cell isolation}

Blood sampling was performed by a certified veterinarian and thus conducted in agreement with the provisions enforced by the Norwegian Animal Research Authority.

Twelve healthy and non-pregnant heifers of NRF at the age of 2-3 years were used in this study, six for the microarray experiment and six for validation of microarray results by RT-qPCR. Blood samples of $200 \mathrm{ml}$ were collected from the neck of each animal in sterile glass bottles with $5 \mathrm{mM}$ EDTA as anticoagulant. Peripheral blood mononuclear cells (PBMC) were extracted by gradient density centrifugation using Lymphoprep at $1600 \times \mathrm{g}$ (Axis-Shield, Kimbolton, UK). The number and viability of the PBMC were evaluated by Countess ${ }^{\oplus}$ Automated Cell Counter (Life Technologies, Carlsbad, CA) and varied between $1.2 \times 10^{8}-6.6 \times 10^{8}$ living cells.

Monocytes were extracted from the PBMC by positive selection of monocyte differentiation antigen CD14+ cells using anti human CD14 MACS MicroBeads (Miltenyi Biotec $\mathrm{GmbH}$, Bergisch Gladbach, Germany) as described by the supplier. Purity of the selected cells was checked by flow cytometry (FACSCalibur) by staining selected cells that had already bound antiCD14 MACS beads with PE conjugated anti-mouse IgG1 (Southern Biotech, Birmingham, AL, USA; 1:200), and was in the range of 95-98\%. CD14+ cells were grown in 6-well dishes at a density of $1.5 \times 10^{6}-2 \times 10^{6}$ cells per well in a RPMI medium supplemented with $1 \mathrm{mM}$ sodium pyruvate, $1 \mathrm{mM}$ non-essential amino acids, $50 \mu \mathrm{M}$ 2-mercaptoethanol and $10 \%$ FCS (all Invitrogen, Carlsbad, USA). The number of wells per individual varied between 12 and 24 .

Cells were left over night at $37^{\circ} \mathrm{C}$ in an atmosphere with $5 \% \mathrm{CO}_{2}$ to differentiate into macrophages and to minimize possible gene expression changes associated with cell stress caused by the isolation procedure. The phenotypic morphology of cells, i.e. differentiation of monocytes into adherent macrophages was visualized and confirmed by phase contrast microscopy.

\section{Bacterial infection}

S. aureus strain 1685-4 isolated from a cow with clinical mastitis was used in the experiment [44]. This strain is susceptible to streptomycin and penicillin. Bacteria were

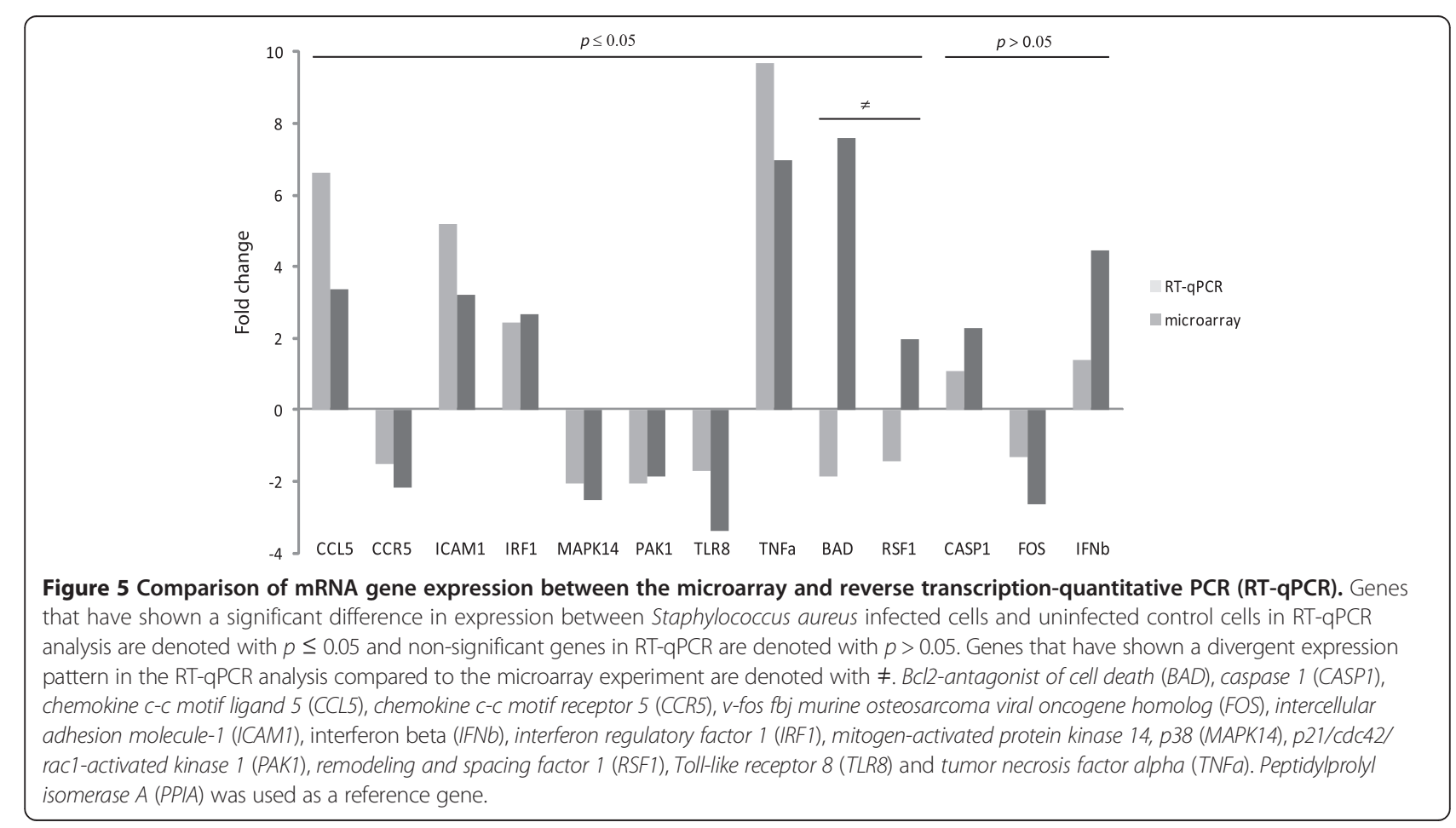




\section{CLASSICALLY ACTIVATED MACROPHAGE}

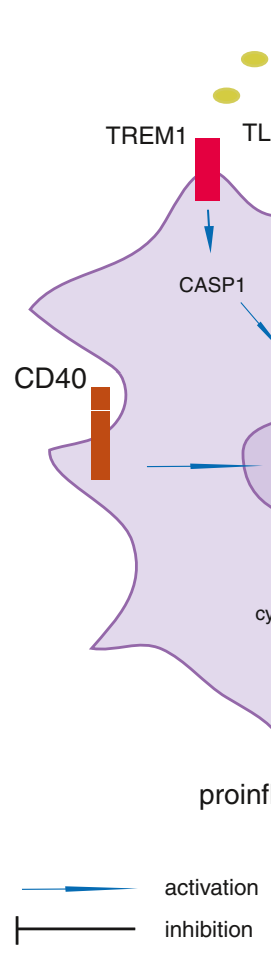

ALTERNATIVELY ACTIVATED MACROPHAGE

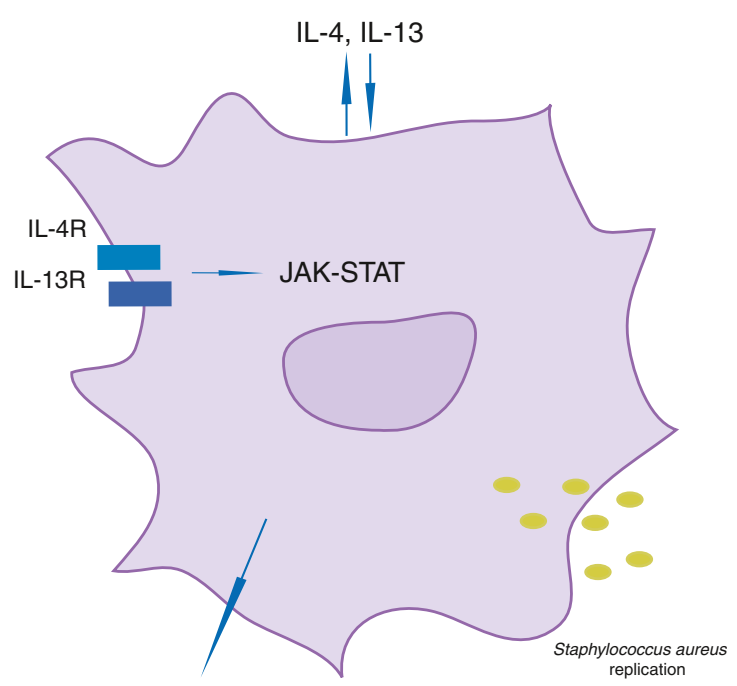

IL-10

Figure 6 Hypothetical mechanism of alternative activation of macrophages in response to Staphylococcus aureus infection. Left panel Staphylococcus aureus enters the macrophage through the Toll-like receptor 2 (TLR2)-dependent pathway that initiates nuclear factor kappa B (NFKB)-mediated temporal inflammatory response. Triggering receptor expressed on myeloid cells 1 (TREM1) synergizes with TLR2 that stimulates intracellular signals resulting in phagocytosis and production of proinflammatory cytokines. NFKB induces expression of co-stimulatory receptor tumor necrosis factor superfamily member 5 (CD40). After phagosomal escape into the cytosol Staphylococcus aureus peptidoglycan induces nucleotide-binding and oligomerization domain 2 (NOD2) expression that in turn triggers inflammation. The macrophage is induced to produce interleukin 4 (IL-4) and IL-13 as confirmed by our study. Right panel - hypothetical alternative activation pathway triggered by IL-4 and IL-13, likely a mechanism by which Staphylococcus aureus evades the host immune response. Alternatively activated macrophage produces anti-inflammatory IL-10, which inhibits classical macrophage activation. Caspase 1(CASP1); interleukin 4 receptor (IL-4R); interleukin 13 receptor (IL-13R); Janus kinase (JAK) and signal transducer and activator of transcription (STAT).

grown in LB broth until mid-log phase. Growth was measured by optical density (OD) at $600 \mathrm{~nm}$ and the final number of colony-forming units (CFU) was determined by serial dilutions and plating on agar. Bacteria used in this study came from aliquots of the same batch.

For each individual the available number of wells with macrophages were grouped into four classes with equal number of wells and cells per class. Two classes were infected with S. aureus in a multiplicity of infection (MOI) of 1 ( 1 bacterium per cell, on average). The two other cell classes were left uninfected as controls.

After $1 \mathrm{~h}$ of infection, the wells were washed twice with PBS and new media containing $60 \mathrm{pg} / \mathrm{ml}$ penicillin and $100 \mu \mathrm{g} / \mathrm{ml}$ streptomycin was added to prevent growth of remaining extracellular bacteria. The control and the infected cells were treated equally. Inhibition of the bacterial growth by antibiotics was verified by microscopy.

Incubation was continued for one additional hour for one of the infected/control class of cells, a total of $2 \mathrm{~h}$ incubation, and for 5 more hours for the other class, a total of $6 \mathrm{~h}$ incubation. Media was aspirated and cells were frozen in the wells and stored at $-80^{\circ} \mathrm{C}$.

\section{RNA extraction}

For microarray experiments, total RNA was extracted by a double extraction protocol. Cells were lysed directly in the wells using Trizol (Invitrogen) according to the manufacturer's protocol. RNA extraction by Trizol was followed by RNA cleanup using RNeasy columns (Qiagen, Hilden, Germany). For RT-qPCR total RNA was extracted using the RNeasy kit (Qiagen) according to the manufacturer's instructions, including on column DNase treatment.

RNA concentration and quality was measured using NanoDrop 1000 (Thermo Fisher Scientific, Wilmington, USA) and 2100 BioAnalyzer (Agilent Technologies, Palo Alto, USA), respectively. All samples used had a RNA integrity number (RIN) above 8 and OD A260/A280 ratio of approximately 2 . 


\section{Microarray experiment}

Samples from six heifers (A-F) were used in the microarray experiment.

The microarray used was a $17 \mathrm{~K}$ bovine cDNA microarray constructed at ARK Genomics (ArrayExpress accession number A-MEXP1592). This array is an expansion of the bovine macrophage (BoMP) specific cDNA array focusing on immune response [45], including a BoMP library generated from stimulated bovine myeloid cells.

Due to the limited amount of RNA available, all samples were amplified using MessageAmp aRNA kit (Ambion, Austin, USA), including incorporation of aminoallyl UTP into the amplified RNA. Cy3 and Cy5 labeling of the aRNA was performed using either $\mathrm{Cy} 3$ or $\mathrm{Cy} 5$ Maleimide mono reactive dye (GE Healthcare Life Sciences, Buckinghamshire, UK) according to manufacturer's instructions, followed by a cleanup procedure using DyeEx 2.0 spin kit (Qiagen).

The $S$. aureus infected samples were labeled with $\mathrm{Cy} 3$, and their respective uninfected control sample from one individual at one time point was labeled with Cy5 and hybridized together to one array. Dye-swap hybridization was performed, i.e. S. aureus infected sample was labeled with Cy5 and the respective uninfected control sample was labeled with $\mathrm{Cy} 3$ and hybridized together to one array. Although a full dye-swap hybridization design for all individuals was preferable [i.e. two arrays per each individual (A-F) per each time point (2 and $6 \mathrm{~h}$ )], the amount of RNA limited the number of dye swaps, resulting in a total of 19 arrays. See Table 6 for the details of dye-swap hybridization and Additional file 6: Figure S1 for experimental design.

Hybridizations were carried out in a GeneTac automated hybridization station (Genomic Solutions, Huntingdon, UK). Post hybridization the microarray slides were washed in wash buffers, post wash buffers and isopropanol. Dried slides were scanned in a Scanarray 5000 XL scanner (GSI Lumonics, Watertown, USA). Images were analyzed using BlueFuse for microarrays (BlueGenome, Cambridge, UK). Spots with poor confidence information, i.e. false discovery rate $(\mathrm{FDR}) \geq 0.05$, were removed from the analysis.

\section{Microarray data analysis}

Normalization and analysis was performed using the Linear Models for Microarray Analysis (LIMMA) package

Table 6 Microarray hybridization design

\begin{tabular}{rccccccc}
\hline & \multicolumn{7}{c}{ No of arrays/dye-swaps } \\
\hline Individual & $\mathrm{A}$ & $\mathrm{B}$ & $\mathrm{C}$ & $\mathrm{D}$ & $\mathrm{E}$ & $\mathrm{F}$ & Total \\
$2 \mathrm{~h}$ incubation & 2 & 1 & 1 & 1 & 1 & 2 & 8 \\
6 h incubation & 2 & 2 & 1 & 2 & 2 & 2 & 11 \\
\hline
\end{tabular}

Uninfected control samples were used as references, i.e. control and Staphylococcus aureus infected samples from one individual at one time point were hybridized to one array. Dye-swap design was used, i.e. uninfected control samples were labeled with Cy5 and Staphylococcus aureus infected samples were labeled with Cy3, and subsequently swap labeling was applied. of Bioconductor [46]. The normalized log ratios for each gene in each of the arrays were analyzed by split-plot ANOVA. The statistical cutoff value was set at FDR $\leq$ 0.05 . Fold change ratios of gene expression comparisons were calculated as a mean of duplicate spots. All arrays (19) were included in these analyses.

The regulated probes $(\mathrm{FDR} \leq 0.05)$ were reannotated to transform probe IDs into gene IDs recognized by pathway analysis software. Annotation was performed by identifying accession numbers in the annotated Ensembl bovine genomic database (ver. 52), by using blastn of fasta sequences against the Ensembl bovine transcripts (blast cutoff e-10) and if still unmatched, to the complete RefSeq RNA database at NCBI (http://www. ncbi.nlm.nih.gov/projects/RefSeq, blast cutoff e-5) as described by [47].

\section{RT-qPCR}

Verification of differential gene expression was performed by RT-qPCR. Six heifers (G-L), additional to the ones used in the microarray experiment were used. Additional individuals were used as no RNA remained after microarray hybridization. Using new samples allows biological verification of the reproducibility of expression data (Additional file 6: Figure S1). Further, $100 \mathrm{ng}$ of total RNA was reverse transcribed, cDNA was then diluted and $10 \mathrm{ng}$ was used for qPCR. First strand cDNA synthesis was performed in triplicate (technical replicates) per sample using SuperScript III Reverse Transcriptase (Invitrogen). qPCR was performed using Power SYBR ${ }^{\circ}$ Green PCR Master Mix (Applied Biosystems, Valencia, USA) according to the manufacturer's recommendations using $20 \mu \mathrm{l}$ reaction volumes. Transcript levels were analyzed using a 7900HT Fast Real-Time PCR System (Applied Biosystems) according to the standard settings of the system software. Thirteen genes were chosen for RT-qPCR analysis, based on their regulation pattern in microarrays, affiliation to selected differentially regulated pathways and their putative role in mastitis pathogenesis based on literature. The genes are BAD, CASP1, CCL5, CCR5, FOS, ICAM1, IFNb, IRF1, MAPK14, PAK1, RSF1, $T L R 8$ and TNFa. Primers were designed using PrimerExpress ver. 1.5 (Applied Biosystems). Primer sequences are presented in Additional file 7: Table S6. A negative control for each RNA sample underwent the cDNA synthesis procedure without reverse transcriptase (no RT control), and negative controls with no added template were included for all primer pairs (no template control). The stability of six reference gene candidates (ATP5B, EIF2B2I, GAPD, PPIA, RPL12I and SDHA) was tested using the bovine geNorm house-keeping gene selection kit (PrimerDesign Ltd, Southampton, UK). Based on the geNorm results peptidylprolyl isomerase A (PPIA) was used as a single reference gene. 
Uninfected samples were used as control and S. aureus infected samples were used as treatment. Fold change for each gene was calculated according to the formula: Fold change $_{\text {gene } \mathrm{x}}=\frac{\Delta C \mathrm{t} \text { treatment }}{\Delta C \text { c control }}$. Both $\Delta \mathrm{Ct}$ treatment and $\Delta \mathrm{Ct}$ control were averaged for the six animals prior to calculation of the fold change, and each animal was treated as a biological replicate. To facilitate interpretation of the down-regulated genes, the reciprocal and multiplied by -1 value of fold change was used. Only $6 \mathrm{~h}$ time point of infection was performed and analyzed.

Initial analysis of the RT-qPCR data was performed using RQ Manager 1.2 (Applied Biosystems). Standard deviation of $\leq 0.3$ per triplicate was accepted. Due to the relatively small sample size in the experiment, a Wilcoxon signed-ranks test was applied for the RT-qPCR data analyses of control and treatment. $p$-values $\leq 0.05$ were considered statistically significant. The statistical software InStat ver. 3 (GraphPad Software, San Diego, USA) was used for the analyses. Correlation analysis between RTqPCR and microarray data was performed in Microsoft Excel.

\section{Pathway and cluster analyses}

The list of differentially regulated on microarray $(n=418)$ and Ensembl reannotated genes was used as an input for pathway and cluster analyses. Moreover, a subset of these genes ( $\mathrm{n}=28$; List eQG from [18]) was also used as an input for pathway analyses. Briefly, the List eQG consist of genes that resulted from combining the differentially regulated genes on the microarray $(n=418)$ with marker positions from a study of QTL affecting susceptibility to mastitis in NRF [26].

DAVID Resources v. 6.7 ([48,49] http://david.abcc.ncifcrf. gov/) was used for initial analysis to identify pathways generated by functional annotation clustering of gene lists and visualize genes on KEGG pathway maps. $p$-values $\leq 0.05$ were considered as significant and no correction for multiple testing was applied. Multiple testing correction techniques are known as conservative approaches and applying them may lower the sensitivity of pathway discovery.

The list of differentially expressed genes on microarray $(\mathrm{n}=418)$ and the List eQG with corresponding fold change ratios were analyzed using IPA (http://www.ingenuity.com). New analyses in IPA were performed for List eQG, due to database update since the last analyses in 2011 [18]. IPA is a curated database and web-based analysis system that identifies the most significant canonical pathways, gene networks, key biological processes and upstream regulators in a set of genes of interest. Each gene from each gene list was mapped to its corresponding human gene ID object in the Ingenuity Pathways Knowledge Base. The resulting lists of genes were used as an input to the IPA library. To comprehend the biological background, significantly associated canonical pathways, biological functions, gene networks and upstream regulators were identified. The significance was determined based on $p$-values calculated using Fisher's exact test, and $p$-value cut-off was set at 0.05 . To summarize the large amount of data generated by IPA, we focused on and discussed selected most affected (top) biological functions belonging to the subgroup 'Molecular and cellular functions', the five most affected (top) canonical pathways, top gene networks and top upstream regulators.

Clustering of arrays (11 from the $6 \mathrm{~h}$ time point) and regulated genes was performed using Cluster 3.0 [50]. The list of differentially expressed genes with their corresponding fold change ratios was used in the analyses. Agglomerative hierarchical clustering with uncentered correlation and average linkage was used to construct the dendrograms. Java TreeView [51] was used to visualize the dendrograms.

\section{Availability of supporting data}

The microarray expression data supporting the results are available in the Array Express Archive with accession E-TABM-1133 (http://www.ebi.ac.uk/arrayexpress/experiments/E-TABM-1133/)

The subset of differentially regulated genes (List eQG) obtained by comparison with data from genome-wide association mapping in NRF cattle can be found in reference [18].

Additional data are included as supplementary material in this paper.

\section{Additional files}

Additional file 1: Table S1. Genes and probes $(n=418)$ differentially expressed in infected cells vs. uninfected control cells $6 \mathrm{~h}$ post infection with Staphylococcus aureus. The genes/probes are clustered and listed in the same order (top to bottom) as in the dendrogram of Figure 1. Asterisk ${ }^{*}$ ) denotes genes used in reverse transcription-quantitative PCR (RT-qPCR) verification of the microarray results.

Additional file 2: Table S2. Significant canonical pathways generated by Ingenuity Pathway Analysis (IPA). A) The list of differentially regulated on microarray $(n=418)$ and Ensembl reannotated genes was used as an input for IPA; B) Subset of these genes ( $n=28$; List eQG from Lewandowska-Sabat et al., Anim Genet 2012, 43:793-799) was used as an input. Asterisk ${ }^{*}$ ) denotes canonical pathways significant after the Benjamini-Hochberg multiple testing correction $(p \leq 0.05)$.

Additional file 3: Table S3. Biological functions identified by Ingenuity Pathway Analysis (IPA). A) The list of differentially regulated on microarray $(n=418)$ and Ensembl reannotated genes was used as an input for IPA; B) Subset of these genes ( $n=28$; List eQG from Lewandowska-Sabat et al., Anim Genet 2012, 43:793-799) was used as an input.

Additional file 4: Table S4. Networks identified by Ingenuity Pathway Analysis (IPA). A) The list of differentially regulated on microarray $(n=418)$ and Ensembl reannotated genes was used as an input for IPA; B) Subset of these genes ( $n=28$; List eQG from Lewandowska-Sabat et al., Anim Genet 2012, 43:793-799) was used as an input.

Additional file 5: Table S5. Upstream regulators identified by Ingenuity Pathway Analysis (IPA). A) The list of differentially regulated on microarray 
( $n=418)$ and Ensembl reannotated genes was used as an input for IPA; B) Subset of these genes $(n=28$; List eQG from Lewandowska-Sabat et al., Anim Genet 2012, 43:793-799) was used as an input.

Additional file 6: Figure S1. Experimental design of microarray and reverse transcription-quantitative PCR (RT-qPCR) experiments. Letters A-L represent individual heifers used in the experiments, i.e. six heifers were used in the microarray and additional six heifers were used in the RT-qPCR; S. aureus: sample where blood monocyte-derived macrophages were infected with live Staphylococcus aureus in vitro; Control: sample of uninfected blood monocyte-derived macrophages; $2 \mathrm{~h}-2$ hours infection with S. aureus; $6 \mathrm{~h}-6$ hours infection with Staphylococcus aureus. For details on experimental design see Methods.

Additional file 7: Table S6. List of primers used for reverse transcription-quantitative PCR (RT-qPCR).

\section{Competing interests}

The authors declare that they have no competing interests.

\section{Authors' contributions}

GMB participated in the design of the study, carried out the infection experiments, microarray and RT-qPCR and has been involved in data analyses and drafting of the manuscript. AMLS performed the pathway and cluster analyses and drafted the manuscript. AD participated in the microarray experiment and performed microarray data analyses. RT contributed to study design and microarray data analyses. AKS participated in study design, infection experiments, flow cytometric analyses and manuscript drafting. IO participated in study design, data analyses and manuscript drafting. All authors read and approved the final manuscript.

\section{Acknowledgements}

We thank T. Tollersrud for providing the S. aureus isolate 1685-4 from a bovine case of clinical mastitis, K. Karlberg for help with sampling of blood from heifers, D. Mouzaki and A.B. Kristoffersen for performing statistical analyses on the microarray data and C. Cabau for reannotation of array probes.

This project was supported by EU FP6-EADGENE (European Animal Disease Genomics Network of Excellence, contract no. FOOD-CT-2004-506416) and the functional genomics programme (FUGE, grant no. 168607) in the Research Council of Norway.

\section{Author details}

'Department of Basic Sciences and Aquatic Medicine, Norwegian School of Veterinary Science, P.O. Box 8146 Dep, NO-0033 Oslo, Norway.

${ }^{2}$ ARK-Genomics, The Roslin Institute and Royal (Dick) School of Veterinary Studies, University of Edinburgh, Roslin, Midlothian EH25 9PS, UK. ${ }^{3}$ Department of Food Safety and Infection Biology, Norwegian School of Veterinary Science, NO-0033 Oslo, Norway.

Received: 10 May 2013 Accepted: 3 December 2013

Published: 17 December 2013

\section{References}

1. Watts JL: Etiological agents of bovine mastitis. Vet Microbio/ 1988, 16:41-66.

2. Fraunholz M, Sinha B: Intracellular Staphylococcus aureus: live-in and let die. Front Cell Infect Microbiol 2012, 2:43.

3. Stout RD, Suttles J: Functional plasticity of macrophages: reversible adaptation to changing microenvironments. J Leukoc Biol 2004, 76:509-513.

4. Atabai K, Sheppard D, Werb Z: Roles of the innate immune system in mammary gland remodeling during involution. J Mammary Gland Biol Neoplasia 2007, 12:37-45

5. Martinez FO, Helming L, Gordon S: Alternative activation of macrophages: an immunologic functional perspective. Annu Rev Immunol 2009, 27:451-483.

6. Avdic S, Cao JZ, McSharry BP, Clancy LE, Brown R, Steain M, Gottlieb DJ, Abendroth A, Slobedman B: Human cytomegalovirus Interleukin-10 polarizes monocytes toward a deactivated M2C phenotype to repress host immune responses. J Virol 2013, 87:10273-10282.
7. Mosser DM, Edwards JP: Exploring the full spectrum of macrophage activation. Nat Rev Immunol 2008, 8:958-969.

8. Gordon S, Martinez FO: Alternative activation of macrophages: mechanism and functions. Immunity 2010, 32:593-604.

9. Schonbeck U, Libby P: CD40 signaling and plaque instability. Circ Res 2001, 89:1092-1103.

10. Arrighi JF, Rebsamen M, Rousset F, Kindler V, Hauser C: A critical role for p38 mitogen-activated protein kinase in the maturation of human blood-derived dendritic cells induced by lipopolysaccharide, TNF-alpha, and contact sensitizers. J Immunol 2001, 166:3837-3845.

11. Karmann K, Hughes CC, Schechner J, Fanslow WC, Pober JS: CD40 on human endothelial cells: inducibility by cytokines and functional regulation of adhesion molecule expression. Proc Natl Acad Sci USA 1995, 92:4342-4346.

12. Lam QL, Zheng BJ, Jin DY, Cao X, Lu L: Leptin induces CD40 expression through the activation of Akt in murine dendritic cells. J Biol Chem 2007, 282:27587-27597.

13. Andrade RM, Portillo JA, Wessendarp M, Subauste CS: CD40 signaling in macrophages induces activity against an intracellular pathogen independently of gamma interferon and reactive nitrogen intermediates. Infect Immun 2005, 73:3115-3123.

14. Kurokawa K, Lee H, Roh KB, Asanuma M, Kim YS, Nakayama H, Shiratsuchi A, Choi Y, Takeuchi O, Kang HJ, et al: The triacylated ATP binding cluster transporter substrate-binding lipoprotein of staphylococcus aureus functions as a native ligand for toll-like receptor 2. J Biol Chem 2009, 284:8406-8411.

15. Zahringer $\mathrm{U}$, Lindner $\mathrm{B}$, Inamura $\mathrm{S}$, Heine $\mathrm{H}$, Alexander $\mathrm{C}$ : TLR2 - promiscuous or specific? A critical re-evaluation of a receptor expressing apparent broad specificity. Immunobiology 2008, 213:205-224.

16. Nakayama H, Kurokawa K, Lee BL: Lipoproteins in bacteria: structures and biosynthetic pathways. FEBS J 2012, 279:4247-4268.

17. Strober W, Murray PJ, Kitani A, Watanabe T: Signalling pathways and molecular interactions of NOD1 and NOD2. Nat Rev Immunol 2006, 6:9-20.

18. Lewandowska-Sabat AM, Günther J, Seyfert HM, Olsaker I: Combining quantitative trait loci and heterogeneous microarray data analyses reveals putative candidate pathways affecting mastitis in cattle. Anim Genet 2012, 43:793-799.

19. Watanabe I, Ichiki M, Shiratsuchi A, Nakanishi Y: TLR2-mediated survival of Staphylococcus aureus in macrophages: a novel bacterial strategy against host innate immunity. J Immunol 2007, 178:4917-4925.

20. Harris J, De Haro SA, Master SS, Keane J, Roberts EA, Delgado M, Deretic V: T helper 2 cytokines inhibit autophagic control of intracellular Mycobacterium tuberculosis. Immunity 2007, 27:505-517.

21. Heinrich PC, Behrmann I, Haan S, Hermanns HM, Muller-Newen G, Schaper F: Principles of interleukin (IL)-6-type cytokine signalling and its regulation. Biochem J 2003, 374:1-20.

22. Hung CS, Liu HH, Huang MT, Cheng CW, Kuo LJ, Ho YS, Wu CH, Chen CM, Wei PL, Chang YJ: Knockdown survivin expression reduces the efficacy of curcumin treatment in hepatocellular carcinoma cells. Ann Surg Oncol 2012, 19:3547-3555.

23. Marsden VS, Strasser A: Control of apoptosis in the immune system: Bcl-2, BH3-only proteins and more. Annu Rev Immunol 2003, 21:71-105.

24. Ulett GC, Adderson EE: Regulation of apoptosis by gram-positive bacteria: mechanistic diversity and consequences for immunity. Curr Immunol Rev 2006, 2:119-141.

25. Koziel J, Maciag-Gudowska A, Mikolajczyk T, Bzowska M, Sturdevant DE, Whitney AR, Shaw LN, DeLeo FR, Potempa J: Phagocytosis of Staphylococcus aureus by macrophages exerts cytoprotective effects manifested by the upregulation of antiapoptotic factors. PLoS One 2009, 4:e5210.

26. Sodeland M, Kent MP, Olsen HG, Opsal MA, Svendsen M, Sehested E, Hayes BJ, Lien S: Quantitative trait loci for clinical mastitis on chromosomes 2, 6, 14 and 20 in Norwegian Red cattle. Anim Genet 2011, 42:457-465.

27. Jain $S$, Chodisetti SB, Agrewala JN: CD40 signaling synergizes with TLR-2 in the BCR independent activation of resting B cells. PLoS One 2011, 6:e20651.

28. Torres D, Barrier M, Bihl F, Quesniaux VJF, Maillet I, Akira S, Ryffel B, Erard F: Toll-like receptor 2 is required for optimal control of Listeria monocytogenes infection. Infect Immun 2004, 72:2131-2139.

29. Berlato C, Cassatella MA, Kinjyo I, Gatto L, Yoshimura A, Bazzoni F: Involvement of suppressor of cytokine signaling-3 as a mediator of the inhibitory effects of IL-10 on lipopolysaccharide-induced macrophage activation. J Immunol 2002, 168:6404-6411. 
30. Dickensheets H, Vazquez N, Sheikh F, Gingras S, Murray PJ, Ryan JJ, Donnelly RP: Suppressor of cytokine signaling-1 is an IL-4-inducible gene in macrophages and feedback inhibits IL-4 signaling. Genes Immun 2007, 8:21-27.

31. Netea MG, Azam T, Ferwerda G, Girardin SE, Kim SH, Dinarello CA: Triggering receptor expressed on myeloid cells-1 (TREM-1) amplifies the signals induced by the NACHT-LRR (NLR) pattern recognition receptors. J Leukoc Biol 2006, 80:1454-1461.

32. Kapetanovic R, Cavaillon JM: Early events in innate immunity in the recognition of microbial pathogens. Expert Opin Biol Ther 2007, 7:907-918.

33. Bougarn S, Cunha P, Harmache A, Fromageau A, Gilbert FB, Rainard P: Muramyl dipeptide synergizes with Staphylococcus aureus lipoteichoic acid to recruit neutrophils in the mammary gland and to stimulate mammary epithelial cells. Clin Vaccine Immunol 2010, 17:1797-1809.

34. Burvenich C, Paape MJ, Hill AW, Guidry AJ, Miller RH, Heyneman R, Kremer WDJ, Brand A: Role of the Neutrophil Leukocyte in the local and systemic reactions during experimentally-induced escherichia-coli mastitis in cows immediately after calving. Vet Quart 1994, 16:45-50

35. Paape MJ, Shafer-Weaver K, Capuco AV, Van Oostveldt K, Burvenich C: Immune surveillance of mammary tissue by phagocytic cells. In Biology of the Mammary Gland. Advances in Experimental Medicine and Biology. Volume 480. Edited by Mol JA, Clegg RA. Kluwer Academic Publishers: New York; 2000:259-277.

36. Riollet C, Rainard P, Poutrel B: Cells and cytokines in inflammatory secretions of bovine mammary gland. In Biology of the Mammary Gland. Advances in Experimental Medicine and Biology. Volume 480. Edited by Mol JA, Clegg RA. New York: Kluwer Academic Publishers; 2000:247-258.

37. Müller P, Muller-Anstett M, Wagener J, Gao Q, Kaesler S, Schaller M, Biedermann T, Gotz F: The Staphylococcus aureus lipoprotein SitC colocalizes with Toll-like receptor 2 (TLR2) in murine keratinocytes and elicits intracellular TLR2 accumulation. Infect Immun 2010, 78:4243-4250.

38. Günther J, Esch K, Poschadel N, Petzl W, Zerbe H, Mitterhuemer S, Blum H, Seyfert HM: Comparative kinetics of Escherichia coli- and Staphylococcus aureus-specific activation of key immune pathways in mammary epithelial cells demonstrates that $\mathrm{S}$. aureus elicits a delayed response dominated by interleukin-6 (IL-6) but not by IL-1A or tumor necrosis factor alpha. Infect Immun 2011, 79:695-707

39. Lutzow YC, Donaldson L, Gray CP, Vuocolo T, Pearson RD, Reverter A, Byrne $K A$, Sheehy PA, Windon R, Tellam RL: Identification of immune genes and proteins involved in the response of bovine mammary tissue to Staphylococcus aureus infection. BMC Vet Res 2008, 4:18.

40. Pisoni G, Moroni P, Genini S, Stella A, Boettcher PJ, Cremonesi P, Scaccabarozzi L, Giuffra E, Castiglioni B: Differentially expressed genes associated with Staphylococcus aureus mastitis in dairy goats. Vet Immunol Immunopathol 2010, 135:208-217.

41. Riollet C, Rainard P, Poutrel B: Cell subpopulations and cytokine expression in cow milk in response to chronic Staphylococcus aureus infection. J Dairy Sci 2001, 84:1077-1084.

42. Tao W, Mallard B: Differentially expressed genes associated with Staphylococcus aureus mastitis of Canadian Holstein cows. Vet Immunol Immunopathol 2007, 120:201-211.

43. Whelehan CJ, Meade KG, Eckersall PD, Young FJ, O'Farrelly C: Experimental Staphylococcus aureus infection of the mammary gland induces region-specific changes in innate immune gene expression. Vet Immunol Immunopathol 2011, 140:181-189.

44. Mørk T, Tollersrud T, Kvitle B, Jørgensen HJ, Waage S: Comparison of Staphylococcus aureus genotypes recovered from cases of bovine, ovine, and caprine mastitis. J Clin Microbio/ 2005, 43:3979-3984.

45. Jensen K, Talbot R, Paxton E, Waddington D, Glass EJ: Development and validation of a bovine macrophage specific cDNA microarray. BMC Genomics 2006, 7:224.

46. Smyth GK: Linear models and empirical bayes methods for assessing differential expression in microarray experiments. Stat Appl Genet Mol Biol 2004, 3:Article3.

47. Genini S, Badaoui B, Sclep G, Bishop SC, Waddington D, Pinard van der Laan MH, Klopp C, Cabau C, Seyfert HM, Petzl W, et al: Strengthening insights into host responses to mastitis infection in ruminants by combining heterogeneous microarray data sources. BMC Genomics 2011, 12:225.

48. Dennis G Jr, Sherman BT, Hosack DA, Yang J, Gao W, Lane HC, Lempicki RA: DAVID: Database for Annotation, Visualization, and Integrated Discovery. Genome Biol 2003, 4:P3.
49. Huang DW, Sherman BT, Tan Q, Kir J, Liu D, Bryant D, Guo Y, Stephens R, Baseler MW, Lane HC, Lempicki RA: DAVID Bioinformatics Resources: expanded annotation database and novel algorithms to better extract biology from large gene lists. Nucleic Acids Res 2007, 35:W169-W175.

50. de Hoon MJ, Imoto S, Nolan J, Miyano S: Open source clustering software. Bioinformatics 2004, 20:1453-1454.

51. Saldanha AJ: Java Treeview-extensible visualization of microarray data. Bioinformatics 2004, 20:3246-3248.

doi:10.1186/1471-2164-14-891

Cite this article as: Lewandowska-Sabat et al:: The early phase transcriptome of bovine monocyte-derived macrophages infected with Staphylococcus aureus in vitro. BMC Genomics 2013 14:891.

\section{Submit your next manuscript to BioMed Central and take full advantage of:}

- Convenient online submission

- Thorough peer review

- No space constraints or color figure charges

- Immediate publication on acceptance

- Inclusion in PubMed, CAS, Scopus and Google Scholar

- Research which is freely available for redistribution

Submit your manuscript at www.biomedcentral.com/submit
C) Biomed Central 